\title{
MIGRACIONES GLOBALES Y CIUDAD
}

\author{
Fernando Fernández Alonso (Arquitecto - Profesor asociado DUyOT)
}

\section{Inmigración internacional desde los años 90}

En los últimos 20 años se han incorporado a nuestra población un número de emigrantes internacionales como nunca se había producido anteriormente. Los cambios que en las ciudades ha implicado este flujo están relacionados con su capacidad de atracción y adaptación, pero tienen que ser considerados también como factores de revitalización o indicadores de decadencia.

Si en 1998 se produjo una entrada de 80.000 inmigrantes, en 2007, el año de mayor afluencia a nivel estatal, la entrada es de 1 millón de inmigrantes, lo que constituía en un solo año el $2 \%$ de la población nacional. El incremento de población empadronada en España en el mismo periodo es de de 5.264.244 individuos, de los que 3.845.483 ha sido de población extranjera, el $73 \%$. Desde entonces y como consecuencia de la crisis, se produce un descenso paulatino, con 500.000 entradas en 2009 y 342.000 en 2013. En este último periodo se produce además un fenómeno inverso, la salida de emigrantes, 300.000 en 2009 y 450.000 en $2013^{13}$. La pérdida de población extranjera no se ha producido por igual en todas las comunidades autónomas. Así, en la Comunidad de Madrid, en el 2007 sigue aumentado la población extranjera (1.001.058 a 1.118.991), hasta el año 2010, cuando se produce un punto de inflexión negativo (868.233 en 2015).

Como resultado de estas avenidas y flujos, nos encontramos con que la población extranjera en el periodo de 1996 a 2010 ha oscilado en esta comunidad del $2 \%$ al $17 \%$ y actualmente está en el $14 \%{ }^{14}$. Las nacionalidades mayoritarias son de Europa (364.527, 41\% total), y América del Sur, Central y del Caribe (301.160, 34\%). Marruecos representa el 9,26\% y China el 6,09\%. Si en 1998 la población rumana en Madrid, el grupo inmigrante mayoritario, eran 717 personas, en 2010 llegó a 210.822 y en 2014, a 199.141 personas. Como la población inmigrante se distribuye en el territorio de la Comunidad de Madrid, en un porcentaje significativo, por nacionalidades, el peso de estas comunidades mayoritarias es todavía mayor.

\section{Una nueva población urbana}

La emigración es fundamentalmente urbana, joven-adulta y familiar: el 44,05\% de los inmigrantes están en el municipio de Madrid, y el $41,46 \%$ en municipios de las coronas metropolitanas, es decir, en espacios urbanos ${ }^{15}$. Hay barrios en los que la

13 LOS FLUJOS MIGRATORIOS EN ESPAÑA DURANTE LA CRISIS. Mario Izquierdo, Juan Francisco Jimeno y Aitor Lacuesta, Dirección General del Servicio de Estudios del Banco de España. Boletín económico, Sep 2014. INMIGRACIÓN EXTRANJERA EN LA COMUNIDAD DE MADRID, Miguel Ángel de Prada, Colectivo Ioé.

14 Datos del Instituto de Estadística de la Comunidad de Madrid.

15 Madrid, Móstoles, Alcalá de Henares y Fuenlabrada son las cuatro primeras ciudades en número de población extranjera, pero son Parla, Coslada y Collado Villalba, entre los municipios con mayor población de derecho, los tres con mayor porcentajes de población extranjera. 
población extranjera llega hoy hasta el 20 y $25 \%$ y municipios en los que lo supera. Los grupos de edad ${ }^{16}$ tienen un gran contraste con la población española en el perfil de 25 a 39 años, con el $40 \%$ de la población extranjera en ese grupo frente al $20 \%$ de la población española, mientras que el porcentaje de la población menor de 20 años respecto al total es casi equivalente en los dos. Si como señala el informe del Banco de España el rápido incremento de ciudadanos extranjeros constituye un importante cambio en la fuerza laboral por edad y nivel educativo, las consecuencias en la ciudad no son menos significativas, más aún cuando la población inmigrante urbana se ha mantenido más resistente a la vuelta a su lugar de origen, pero los ciclos y fluctuaciones dependen de factores exógenos y globales. La inmigración supone en muchos barrios un relevo importantísimo de la población característica, de grupos de edad y sociales completos, pero no sabemos con seguridad cuántos de ellos están en los barrios para quedarse a largo plazo.

\section{Asentamiento de la inmigración en la ciudad consolidada}

Los inmigrantes se han asentado en todo tipo de barrios de la ciudad, excluyendo zonas de alto nivel económico con tipologías muy homogéneas, concentrándose en base a tres circunstancias: la disponibilidad de vivienda en alquiler o alojamiento barato, variado y rápido; la agrupación familiar o de colectivos y nacionalidades en un entorno muy cercano; y la cercanía al lugar de trabajo, por la reducción de costes de desplazamiento y en relación con algunas actividades, por el incremento de productividad y oportunidades. Muchas de las actividades económicas en las que se ocupan los emigrantes (servicios de hostelería, mantenimiento y limpieza, transporte, asistencia a hogares y cuidado de enfermos y ancianos, construcción) se realizan de forma independiente y ocasional, y con frecuencia a partir de redes familiares o de amigos, lo que requiere de proximidad.

Al contrario de la inmigración rural que dio lugar al crecimiento de la periferia madrileña en procesos ordenados e informales, la inmigración internacional se asienta en la ciudad consolidada. Los inmigrantes han ocupado una parte específica de las ciudades que en muchos casos acusaba problemas de obsolescencia, aportando a cambio vitalidad, actividad, negocios y cambios culturales. Esta población mantiene fuertes vínculos con sus barrios por cuestiones económicas, de proximidad, familiares, de grupo e identidad, incluso de seguridad, lo que ha favorecido la recuperación de estructuras de barrio y cercanía ajenas a las dinámicas de dispersión comercial y de ocio en la periferia. La baja cultura española de reocupación o recuperación de tejidos consolidados se ha visto compensada por la inmigración.

Los migrantes llegaron cuando las expectativas económicas eran muy altas, la ciudad se estaba expandiendo, y la población local buscaba nuevos lugares y tipologías para desarrollar programas vitales distintos. Se ha producido un intercambio de rentas que permitió a la población local la salida de sus barrios tradicionales y a la población emigrante la adquisición o alquiler de una vivienda, con distintos grados de habitabilidad, dignidad e integración urbana, muy precaria en muchos casos. La segura permanencia de gran parte de la segunda generación en su

\footnotetext{
${ }^{16}$ Informe de la población de origen extranjero empadronada en la Comunidad de Madrid. Observatorio
} de Inmigración del Centro de Estudios y Datos de la Comunidad de Madrid. Enero de 2015. 
nuevo país y la gran capacidad de ahorro de las familias inmigrantes, auguran que la población inmigrante no permanecerá en estas zonas, y que se trasladarán (y dispersarán) por la ciudad y el área metropolitana.

La ciudad y sus barrios han ganado a cambio la renovación y el mantenimiento de la edificación y la actividad local por vía de la nueva población, pero no es menos importante que los conflictos de integración sean puntuales, y que, en mi opinión, la inmigración contribuya a crear un nuevo acervo multicultural, disolviendo la homogeneidad de las visiones autóctonas familiares, colectivas y políticas. Los emigrantes ocupan la calle, parques y espacios públicos de una forma activa, organizada y respetuosa. La calle es, para ellos, un lugar de integración y celebración colectiva, mediante el deporte en grupo, la comida, el encuentro; que sea evidentemente barata refuerza la disponibilidad para este uso.

\section{Integración e inestabilidad}

En los periodos señalados la inmigración ha introducido en la ciudad unos tipos de diversidad e inestabilidad diferentes a los habituales, de carácter global y fuertemente percibidos por sus habitantes; la resistencia y adaptabilidad de los tejidos urbanos a nuevos escenarios cuantitativos y emocionales ha definido y definirá la vida de numerosos espacios de nuestras ciudades.

La integración de la diversidad está avanzada en los programas sociales y económicos con distintos modelos y grados de avance, y está desgraciadamente condicionada por los problemas de gestión de la creciente precarización social y del empleo. La conservación de la ciudad tradicional y la rehabilitación de barrios forma parte de la planificación urbanística; pero es necesaria una reflexión profunda sobre quiénes son los nuevos habitantes que la han ocupado y actualmente la utilizan, sufriendo gran parte de sus peores condiciones de habitabilidad.

Como actores de la ciudad, y hemos visto que en gran número y proporciones muy altas sobre la población tradicional, los colectivos inmigrantes van a participar en su futuro en la medida en que se consolide su permanencia. Y lo harán imponiendo quizás nuevas formas de entender la conservación y rehabilitación, el papel de los equipamientos, el espacio público y la movilidad.

Con escenarios y evoluciones ligados a cambios globales, o simplemente por el deseo de retorno a la nación de origen, la inestabilidad del número y carácter de la nueva población inmigrante es un nuevo factor de planificación. Los barrios pueden pasar a formar parte de las piezas de juego de una economía global, como lo es el suelo de actividades económicas. Los barrios y viviendas en los que los inmigrantes se han asentado, que eran frágiles ya antes de su llegada, pueden estar sometidos a dinámicas de abandono, deterioro, reocupación o incluso gentrificación para las cuales será necesario establecer estrategias de resistencia y adaptabilidad. 